\title{
The introduction of design to policymaking: Policy Lab and the UK government
}

\author{
Jocelyn Bailey* and Peter Lloyd \\ University of Brighton \\ *joss.bailey@gmail.com \\ DOI: 10.21606/drs.2016.314
}

\begin{abstract}
The use of design within government institutions is a rapidly accelerating trend of global dimensions. The emergent nature of these design practices, and cultures, raises questions about what exactly is happening in the interactions between design and political institutions, and how that might be understood in broader socio-economic and political terms. This paper reports on a series of interviews with senior level civil servants working in UK central government, all of whom have had some exposure to design methods and techniques through interaction with the UK Policy Lab. The paper sets out the ways in which the epistemology and practices of design, as introduced through Policy Lab, both expose and challenge those of the political institutions and policy professionals they seek to change.
\end{abstract}

Keywords: design, design thinking, policymaking, politics

\section{Introduction}

In recent years there has been a growing interest in design by governments seeking to innovate practices of governing. A number of administrations are experimenting with approaches derived from participatory, co-design, and service design, to improve service delivery and develop strategy and policy. The phenomenon is beginning to feature in design research: through mapping exercises undertaken, for example, by the Parsons New School for Design Desis Lab, Reos Partners, and Social Design Futures (Armstrong et al, 2014). It is also reflected in the emergence of conferences (such as Labworks 2014 and 2015), websites (such as researchingdesignforpolicy.wordpress.com and policy-design.org), books (Bason 2014, Jefferies et al 2013), PhDs (Christensen 2015) and a journal ('The Annual Review of Policy Design', 2013). 
Much like other governance reform movements, the drivers for the adoption of design within different administrations are presumably various - and can be subjected to critique from across the spectrum of political standpoints (see Leggett for an analogous critique of 'nudge' techniques): the further encroachment of neoliberalism and the logic of the market, or a sincere attempt to improve the lives of citizens by better adapting to a $21^{\text {st }}$ century problem field (Dunleavy et al, 2005), preventing 'blunders' (King and Crewe, 2013), and orienting administrations away from their own institutional perspectives. As it enters the world of government decision-making, it is timely to reflect on how design is being mobilised to extend and enable techniques of governance. Approaching the subject through a governmentality (Foucault 1991, Miller and Rose 1988, Tunstall) frame opens up a deeper and more critical analysis.

Building on research that sees design as a contingent and situated set of practices (Kimbell 2013, Shove 2007), and design cultures as specific to, even generated by, social, economic and political systems (Julier 2007, Dilnot 2014), this research seeks to extend existing accounts of the uses of design in government, and particularly in strategic-level decision making, by attending to the specificity of the political context within which these design cultures are emerging. In order to begin to understand what design is doing in policymaking, and how that might be read within wider political narratives, a study was conducted focusing on the first year of work of the UK Policy Lab ${ }^{1}$ (see also Kimbell 2015).

Policy Lab is a small team within the Cabinet Office (the central department of the UK government responsible for supporting the prime minister and their cabinet), established in 2014. The remit of Policy Lab is to support policymakers to transform their approach to policymaking by demonstrating new tools and techniques, generating new knowledge and skills, and facilitating a long-term shift in policymaking practice. This study consisted of a series of interviews with senior civil servants, all of whom have had contact with or experience of working with Policy Lab.

This paper focuses first on what these interviews reveal about what design is doing in policymaking, and, second, considers the potential for critical readings of this trend from a broader governmentality perspective. What is perhaps most interesting is not so much an account of the insights, ideas and proposals that a design-based approach can generate - all of which it might be possible to predict from a reading of the design thinking literature (both academic and popular accounts: Brown 2009, Martin 2009, Cross 2001, Dorst 2015, Buchanan 1992, Michlewski 2008, Kimbell 2011) - but what happens when this approach to problem-solving collides with a specific institutional culture.

\section{Method}

Fifteen interviews were undertaken, over the period May-July 2015, with a focus on the specific effects of Policy Lab's design methods and approach, and particularly the distinction between this kind of practice and 'normal' civil service practice. The research reported in

1 https://openpolicy.blog.gov.uk/category/policy-lab/ 
this paper was conducted as part of a wider study by BOP Consulting (for whom the first author was working at the time) assessing the impact of Policy Lab in its first year of operation. Interviewees were approached initially to inform the impact study, and as part of that conversation consent was obtained to use these texts for the purposes of the research reported here.

For the interviews the Policy Lab team proposed a longlist of participants that encompassed a range of levels of seniority, types of project, and points of view (they were asked to include people they knew to be sceptical about their methods as well as enthusiasts), from which 15 civil servants from 8 government departments (shown in Table 1, below) were selected for interview. Most were interviewed in person in their own departmental environment (a small number of interviews were conducted by telephone), and these conversations were recorded and transcribed.

Table 1. UK Government departments of interviewees

\begin{tabular}{ll}
\hline Government Department & Number of Interviews \\
\hline Department of Business Innovation and Skills & 1 \\
\hline Department of Work and Pensions & 3 \\
\hline Ministry of Justice & 2 \\
\hline Department of Health & 1 \\
\hline HM Revenue \& Customs & 1 \\
\hline Office of the Deputy Prime Minister & 2 \\
\hline Home Office/ Police & 2 \\
\hline Cabinet Office & 3 \\
\hline
\end{tabular}

The transcribed text of the interviews were reviewed and revealed a number of commonly recurring themes. Some of these relate specifically to the perceived attributes of design, and are drawn out in section 3.2. However others were reflections on the culture and practices of the civil service and the political institutions it serves: the hierarchical structure and choreographed processes, the particular organisational aesthetic, the way knowledge is understood and intelligence and skill are performed, and the timing and rhythms of politics itself. This second set of themes is discussed in more depth in sections 3.3-3.7, drawing extensively on phrases and quotes from the interview transcripts. Interviewees have been quoted anonymously, including omitting job titles that in certain cases would make them identifiable, given the sensitivity of some of the subject matter.

Because of the pre-existing relationship with Policy Lab, and the purpose of the conversations being an open and frank assessment of the team's work, these interviews represent an unusually candid set of views from senior civil servants about their institution and its policymaking practice and culture. As such they offer a unique opportunity to understand how civil servants are making sense of design practices. 


\section{Design in policymaking}

\section{Design approaches to policy problems}

What does 'design' mean in a policymaking context? Policy Lab markets its offer as contributing 'design, data and digital' capabilities to the suite of policymaking tools used in government (RSA Journal 2014). Engagements with civil service teams range from two-hourlong introductory workshops, to projects lasting several months. In such engagements 'design' refers to:

- modes of research that explore lived experience, often based on design ethnography;

- collective inquiry;

- the use of provocations and speculations as a research probe;

- generative techniques drawn from co-design and co-production;

- collaborative creativity;

- modelling techniques such as prototyping; and agile project methodologies.

These activities take place in settings and through conversations facilitated by a range of materials: coloured pens and paper, post-it notes, play-doh and craft materials, co-design templates such as personas or user journey maps, and other prompts such as photographs and visual materials.

Table 2 (below) lists some of the projects delivered by Policy Lab in its first year, in partnership with the government departments listed in Table 1, and other external agencies.

Table 2 A selection of policy challenges addressed by Policy Lab.

\begin{tabular}{lll}
\hline Project name & $\begin{array}{l}\text { Department/ } \\
\text { team }\end{array}$ & Project description \\
\hline $\begin{array}{l}\text { Family } \\
\text { Mediation }\end{array}$ & Ministry of Justice & $\begin{array}{l}\text { How can divorcing couples be persuaded to } \\
\text { mediate, rather than going to court - which is } \\
\text { more costly for everyone involved. }\end{array}$ \\
\hline $\begin{array}{l}\text { Policy } \\
\text { Profession }\end{array}$ & $\begin{array}{l}\text { Policy Profession } \\
\text { Sussessment }\end{array}$ & $\begin{array}{l}\text { Rethinking the way that the performance of } \\
\text { policy professionals is measured, and their } \\
\text { careers are supported, to help those civil } \\
\text { servants better understand how to develop their } \\
\text { skills and capabilities as policymakers. }\end{array}$ \\
\hline $\begin{array}{l}\text { Disability and } \\
\text { Health } \\
\text { Employment }\end{array}$ & $\begin{array}{l}\text { Department of } \\
\text { Work and } \\
\text { Pensions and the }\end{array}$ & $\begin{array}{l}\text { How can disabled people, or people with health } \\
\text { conditions who are at risk of unemployment, be } \\
\text { kept in work to avoid the personal cost of } \\
\text { potential long-term unemployment, which can } \\
\text { exacerbate health conditions. }\end{array}$ \\
\hline $\begin{array}{l}\text { Houng People } \\
\text { and National } \\
\text { Insurance } \\
\text { Numbers }\end{array}$ & $\begin{array}{l}\text { HMRC (Her } \\
\text { Majesty's } \\
\text { Revenue and } \\
\text { Customs) }\end{array}$ & $\begin{array}{l}\text { How might young people be encouraged to look } \\
\text { after their National Insurance number once } \\
\text { received, and how can this interaction act as the } \\
\text { start of a life-long relationship between citizen } \\
\text { and government? }\end{array}$ \\
\hline
\end{tabular}




\section{An Emerging Design Culture}

Interviewees were asked directly what was different, useful, or problematic about using a more designerly approach to developing policy. All 15 interviewees acknowledged a need for change in policymaking practice, whether that is to do with meeting the demands of an austerity regime, a recognition that some policy - especially social policy - has systematically failed to achieve what it is meant to, or for the sake of improving policymaking as an 'art' in its own right. As a response to that need for change, the design that they had been introduced to was recognised to offer something of value, the accounts of which were familiar from existing accounts of the value of design and 'design thinking'. To mention a few instances, they commented on:

Different modes of evidence gathering, producing new and different kinds of insight:

"as a technique it was really successful in getting a group...into thinking about the future. It structured the responses they gave, so it made what they said more structured and more usable."

Reordering the hierarchy of evidence:

"There are multiple considerations and it added more power and authority to some. It gives them a status they might not otherwise have. Like some of the softer things around user experience."

Enabling more open thinking:

“the people who normally would start by saying 'that'll never happen' - it swept that out the way."

Engendering collaboration and buy-in:

"Although I probably could have predicted the outcomes we arrived at, the process was vital for getting buy-in from a larger group of stakeholders."

Reconfiguring relationships between people:

"The primary impact is that senior people are now engaging with each other on a list of solutions... whilst there are still multiple hurdles to achieving policy change, there is now a very clear conversation going on."

Translating evidence and insight into ideas (for policies):

"They came out with some very basic stuff that just would never have occurred to me... the ideas are not complex but they're coming from an angle completely different to mine."

In these conversations, design was discussed primarily in terms of 'tools', 'methods', or 'techniques' that might be applied. This is partly to do with how Policy Lab has presented itself in order to encourage the adoption of its practices. But it reinforces the perception that all that needs to happen is for civil servants to pick up some new policymaking tools as they might a hammer or a screwdriver. The service Policy Lab provides is conceived of as "access to some techniques that weren't within their skillsets", rather than a shift in how government thinks about problems and its capacities to 'solve' them. Within the narrow 
view of rational choice and other traditional linear models of policy decision-making, design can simply be read as a set of methods that generate a greater number of options from which to choose at a given point in the process. But it is also possible to see what Policy Lab is doing with design as generating an entirely different decision-making model for policy (Considine 2012).

So, what do our interviewees think? And if, as has been proposed within debates about design research practice (Dorst 2008), we expand our focus from 'the process', to encompass object, actor and context, what might these interviews reveal beyond the critique of a set of design processes? In many cases, although interviewees made overt statements about the usefulness or not of Policy Lab's tools, implicit in their answers was a suggestion that Policy Lab's approach is challenging in a more fundamental way.

\section{Whitehall policymaking culture ${ }^{1}$}

Imprinted on these conversations about design is the image of a powerful institutional culture, and a feature of all the texts is the conflict between this culture and the design 'tools' on offer: conflicts around what is considered to be knowledge, intelligence, and skilled practice, around the aesthetics of the institution, and around the nature of political relationships and timescales.

The qualities of the Whitehall policymaking community's 'culture' emerge in the interviews in several ways. As an attention to hierarchy: people make overt statements about their 'grade' ${ }^{2}$ and the implications of that, and exhibit a general upwards-facing orientation. Information is constantly being filtered and delivered up through the hierarchy, with permission and decisions flowing back down in return. This is perhaps not surprising given the top-down nature of ministerial control of departments.

Conversations were peppered with the names of men: there is a tendency to refer to the very senior civil servants by first name only, indicating an assumption of familiarity with noteworthy and significant people. (By contrast, political figures are typically referred to by their placeholder title: 'the minister', 'the PM', 'the chancellor'.) This raises a question about the gendered nature of policymaking culture, and whether intelligence is performed here in gendered ways. The language certainly conveys an impression of some implicit notions of intelligence and skill, defined as individual and personal cleverness, quick-thinking, a facility with words and text, and the ability to mediate and navigate the vicissitudes of politics.

The following extract encapsulates several of these traits:

"The policy profession also needs to be brilliant at the stuff that Jeremy is brilliant at being one step ahead of the ministers, always being trusted, a brilliant mind, knowing how to commission some quick advice, all the classic Whitehall stuff. That stuff is immensely valuable... And we would be absolutely sunk without the Chris Martin,

\footnotetext{
1 'Whitehall', as well as being the name of a road, is commonly used to refer to the community of central government departments clustered around Westminster and the Houses of Parliament in London.

${ }^{2}$ Civil servants' seniority and position in the organisational hierarchy is denoted by numbered 'grades'. It is not uncommon for civil servants to introduce themselves by stating their grade.
} 
Jeremy Heywood* skills. Completely sunk. If the PM thought that Jeremy couldn't come up with the sorts of things that would give the Prime Minister the ability to stand up and say 'we'll crack immigration', then Jeremy loses his license to operate, and we all lose our license to operate."

*Chris Martin, Director General, Prime Minister's Office, and Sir Jeremy Heywood, Cabinet Secretary and Head of the Civil Service

Packed into this brief extract are references to talented men, thinking and acting decisively, manoeuvring in order to strategically position the civil service in relation to the politicians it serves. In other conversations, references to the format of 'ministerial submissions' highlights a set of established practices, and ways of managing relationships, when working between ministers/ Parliament and the civil service. Rather than anything so clear as a set of rules, this might be more accurately likened to a carefully choreographed scene constantly being played out - where those who are artful can make small innovations within an established form. And whilst interviewees were prepared to admit the limitations to traditional ways of making policy, and the need for change - there is also a strong sense of loyalty to this institutional culture. It is this context that design plays into and the confrontation reveals several challenges.

\section{Concepts of knowledge and the performance of intelligence}

In 'How Institutions Think' Mary Douglas (1986) sets out an argument for 'the sociological dependence of all cognition': within the social milieu of the civil service we can assume there might be some common epistemological bases. As it emerges in these interviews, intelligence appears to be understood as individual brilliance, as the capacity of one person's brain - as opposed to embodied, contextual, situated, or social intelligence. The complexities of policymaking are only for the brightest sparks:

"bad policymaking [...] I've seen a couple of examples in the department I'm about to go to - a submission which is (by) someone reasonably clever but not very clever"

The assumption here is that only if people are 'very' clever can they achieve the goal of good policymaking - the onus is very much on the capability of the individual. Knowledge is generated through description rather than acquaintance: for example, reviewing certain kinds of historical evidence or data, understanding the range of potential solutions that are acceptable, applying the analytical and critical capacities of an individual, or asking a known expert are all commonly accepted ways of generating knowledge; learning through action or testing or immersion in an environment or asking a non-expert are not. The following quote illustrates the rarity of the latter:

"And she said 'the thing is, we've been working on this for ages but we've never thought about what the experience of those who used our service was. We've never done that.' With that sense of 'my god, how come we never did this?!'”

The answer to that question, 'how come we never did this?', is presumably that asking people about their experience of a service simply isn't considered a relevant or useful thing to do, or a valid way of generating knowledge. And even when experts are involved, there 
are still only certain kinds of information considered robust enough to constitute 'evidence'. For instance, once quite senior researcher commented:

"I struggle to see how ethnography and observational research on its own could possibly capture the richness that's out there in the data."

Although design ethnography as a research method for informing policy is understood as helpful in that it reveals new insights, it is also problematic for policymakers in that it isn't accepted as sufficiently representative, quantifiable, or reliable. The challenge for design in this context, then, is epistemological: of conflicting beliefs about how one might come to know things about the world, about what is considered a valid way of knowing. Designerly ways of knowing (Cross 2001), it seems, are rather different to policymaking ways of knowing.

\section{Notions of skilled practice}

Skilled practice in these interviews is characterised by accounts of manoeuvring and handling, of quashing ambiguity and providing certainty, rather than necessarily finding an appropriate solution to a problem.
"if there is an answer, we go for it. Because that's the easiest thing to do. I could have presented a brilliant submission to a minister on inner city pregnancy, and had all the data to support it, and it might have been a great bit of work, and it's quick and it's neat - but it might have been entirely the wrong intervention."

This extract highlights two issues: the speed at which policymakers are encouraged to produce solutions, and the fact that sound ideas on their own are rarely enough - or even required - in politics. It is a mistake to assume that design might get itself license to operate simply by generating great ideas that stand a chance of working. As we will go on to discuss, the factors that influence the adoption of an idea are rarely to do with the quality of the idea itself. Civil servants are on the lookout for "good ideas we can land".

Problematically, some design methods implicitly ask civil servants to compromise (what they understand to be) their performance of professional competence:
"you have to be very careful when you say to a Minister 'none of these things have worked before, we don't really know exactly what to do now, and we'll have to bring in other people to help us find a solution.' Because as an official you want to be able to give options and show that you know what you're doing. And actually being able to say 'we're in a space where there's a lot of ambiguity, and we're going to dwell in that ambiguity, and I want you to give me time to do that.' That's quite tricky."

Relations between the civil service and politicians are subject to some rather complex power dynamics, which makes it very difficult for either party to admit that they don't know what to do. The need to provide clarity and certainty, which is driven by the dynamics of politics, does not create an environment conducive to working in a designerly fashion, where one can "sit back and think in a more reflective way", or "probe-sense-respond". In this way design as a tool in the policymaker's toolbox suffers the same fate as any other kind of evidence-generating activity: 
"The generation of ideas on the back of the data? Well, as generally speaking we don't surround ourselves with data, I imagine that skill must be lacking."

\section{Aesthetic disruption}

As demonstrated by Gagliardi (1999), all organisations have an aesthetic, a set of ways the institution manifests itself to the senses. For the departments of government, and policymakers, the dominant aesthetic is closely tied to words and text: the circulation of pieces of paper with words written on them, the act of sitting around in meetings with words on paper on the table, the writing of ministerial submissions in a predefined format. In contrast design operates in a less text-dependent way.

"(what) I found very interesting was the graphic, visual side of it, which is not civil service at all. I personally still operate by writing essays. It's about the only job under the sun that writing A Level essays is actually useful for."

Words are clearly felt to be reassuring evidence of analytical work having been done, of deep knowledge, and the passing and filtering of knowledge through text denotes a person's place in the hierarchy and was clearly the general expectation:

"After this I'm going to a meeting to discuss some thorny issues, and we tackle it by producing a load of paper with tabs and words. That's what l'd expect for most policy meetings that I attend."

The same interviewee joked that "you know you've made it when your team makes you such a beautifully tabbed briefing". Knowledge is managed through the production, ordering and reordering of text, and the more senior you are, the more stages of filtering and ordering have happened before at text reaches your desk.

The staging of meetings themselves reproduces hierarchies and particular ways of performing cleverness - such as the ability to (appear to) assimilate information rapidly, and be decisive:

"That forum creates the mentality that you have to be quite focused and narrowminded. There's a long agenda and you've got to get to action points."

One interviewee gave an account of a meeting where she had a very brief opportunity to make the case for a particular course of action to her seniors - not enough time in her view to be able to communicate sufficient information - and a questionable (in her view) decision was subsequently made. The format and structure of the meeting dictated the nature of the policy decision, rather than the other way around.

Although 'design thinking' has been accused of downplaying the importance of aesthetic judgment in the designers' skillset (Tonkinwise 2011, Brassett 2015), aesthetic disruption is a leading feature of these interactions with design. Design presents the challenge that there might be other ways of learning, negotiating and collaborating, unrelated to the production of texts. And by changing the physical and aesthetic configuration of people in relation to each other, and in relation to a common problem, it introduces a different social dynamic. This is both its potential to generate different kinds of knowledge, different ideas, and to 
reconfigure relationships to become more productive. But so clearly challenging some established forms also puts it at risk of being rejected. This is compounded by the apparent superficiality, or non-seriousness, of some of its aesthetic modes:

"I'll need to manage the situation quite carefully, to make sure they go 'slowly slowly catchy monkey' on them. Don't bring out the cartoons and lego straight away."

People whose work lives revolve around highly ordered meetings and texts, the need to appear quickly decisive, and to manage some incredibly challenging issues, can unsurprisingly see the 'playfulness' that design methods introduce as inappropriate.

\section{The rhythms of politics}

There are two further ways that bringing design into policymaking seems to be at odds with the forms of politics. The first is a timing issue - senior civil servants often have to react very quickly to changing situations, a mode of working that has led to a set of formulaic practices and patterns. Opening that up is often not welcome:

"When there's a crisis, the immediate focus is on producing some advice, a handling plan, some legal analysis. You immediately go into product mode. It's hard to step back and think 'what are the different ways of addressing this? Is there another route we could be pursuing?' Because the machine needs to be fed and the machine likes linear things."

Second, is the more fundamental issue of democratic accountability. There are two aspects to this. Current practices exist within what is understood to be a legitimate political decisionmaking process (however flawed in reality), where a course of action is negotiated and decided through the enacting of politics in a more or less public arena. The behaviour and work of departments under ministers mirrors that playing out of priorities and decisionmaking; difficult conversations which can't necessarily be effaced:

"The Policy Lab guys [...] (are) assuming that everybody is willing to participate in a collaborative creative process, whereas actually, with inter-departmental working that's often not the case. People sit there, and say nothing, and lock the conversation down [...] At the end of the day it stems from - what a lot of people would say are healthy disagreements between ministers. And their strategic thinking about the direction of policy."

The perceived advantages of some design methods include engendering collaborative working - but in an agonistic relationship such as that which exists between departments and ministers who have differing views about the nature of, and appropriate response to, a problem, collaboration is not necessarily what either party is seeking to achieve. Design here needs a better account of what role it might play in mediating, rather than glossing over, political opposition.

Finally, it is evidently difficult for civil servants to tell an elected official that their problem definition and solution are 'wrong', particularly when those characterisations of a problem may well have been part of a party's manifesto promise. 'User research' and 'prototyping' of new policies risk short-circuiting the traditional decision-making structure by circumventing 
the political arena. The most design can hope to do here is better 'inform a discussion with ministers':

"We're all about evidence-based policymaking. However the reality is sometimes it's policy-based evidence making. You've got to be mindful that there is a predefined solution. And you are there to make it happen."

Most of the interviewees were clear that design - rather than promising 'magic wand' solutions - needs to mind its place in the hierarchy.

\section{Designing in an unavoidably political context}

The design practices Policy Lab is introducing are fundamentally challenging some existing notions of intelligence and knowledge (by positioning them as situated, embodied, social, contingent, experiential, etc), and the accepted ways of performing intelligence - and they are partly doing that by aesthetic means. They are also at odds at times with the demands and expectations of a 'political' institution. So notwithstanding the ability of these designerly methods to generate new understandings of problems, and new solution possibilities (Kimbell 2015), there are cultural and epistemological factors at play which will determine the extent to which these things are mobilised.

As Table 2 showed, the subject matter of the (social) policy challenges discussed in this research lands them squarely in reach of a governmentality critique (Foucault 1991, Miller and Rose 1988): the majority of these projects are concerned one way or another with the manipulation of behaviours, the deployment of 'the subject's capacity for action' (McKee, 2009). Personal responsibility and the capacities of individuals are being mobilised (through designerly practices) to achieve the goals that government seeks. A critical perspective also allows us to see trends such as depoliticisation (Flinders 2014), libertarian paternalism (Jones et al 2010), and particular economic narratives (Wren-Lewis 2015) playing out through policy conversations and the development of new types of intervention. The ends of government, as is clear from the interviews, are currently strongly tied to an austerity narrative; saving money and resources, and achieving greater efficiencies:

"Even if we did it better, and were more democratically accountable, and the solution was much more acceptable to the British public - that's not really quantifiable."

It is arguable that the pressure to be accountable and frugal in the distribution of public money eclipses the wellbeing of citizens as a driving agenda - it is for this purpose rather than his or her own welfare that 'the user' is targeted as a focus of research. And so it is clearly possible to read design as being exploited (as so often) by a system, subordinated to its political aims (Dilnot 2014).

However one could make such critiques of any and all social policy tools in a neoliberal democracy (Swyngedouw 2005). And there are limits to a governmentality-led critique. In this case perhaps we could give more credit to the agency and motives of the practitioners in question, who (by the evidence of these interviews) are perfectly aware of the ethical difficulties of their terrain: 


\begin{abstract}
"Policy is a big word that covers a lot of things, the centre ground is in making difficult - sometimes impossible - trade-offs between multiple competing aims, with limited resources, in a political context."
\end{abstract}

Our interest here is whether there are ethical or political questions for design (and designers) that are somehow different to the questions any reflective policy practitioners might ask themselves. If we accept the 'silent, ordinary, fully routinised' apolitical institutions of the civil service are, in fact, where politics and governmentality is daily enacted (Latour 2007, Stone 1988), do we expect more criticality of design than any other discipline? Does design, with its capacities to expedite solutions, to make new things knowable and therefore governable, have a special responsibility? At the very least, we cannot possibly continue to see design as a 'neutral' or value-free set of practices. The very act of defining a user involves political reasoning (Stone 1988, Wilkie and Michael 2009), and the notion of the singular 'user' itself belies a conception of 'the social' that (for example) presumes the existence of individual autonomy, and privileges the individual over the community. Along with other practitioner-academics, we are interested in the question of design's ethical and critical preparedness for intervening in social and political contexts:

"The deployment of Design Thinking in social issue domains such as poverty, health, and education, is increasingly widespread. There is an urgency for Design Studies to be critically evaluating these projects and showing strong leadership in terms of recommending certain approaches and resisting others." (Tonkinwise 2014)

\title{
Conclusion
}

Policy Lab's work in the Whitehall policymaking and civil servant community is design tailored to a specific context. Whilst the team members are a mix of experienced designers and civil servants, the lab itself is only 2 years old, ${ }^{1}$ and continually developing its practices. Other studies of Policy Lab previously mentioned (Kimbell 2015, BOP Consulting) have focused on evaluation for improvement and efficacy. This account is intended to be more reflective and critical about what it is that introducing design problematises in the institution of government. We are currently planning further studies that take a similar approach in comparable contexts (in Scotland, for example). Looking across a number of design-in-policy practices, and looking more closely at the content of specific policy problems, should lend itself to further exploration of these evolving design practices through a governmentality lens, deepening understanding of how design is being mobilised in strategies of governance.

Acknowledgements: We would like to thank the two anonymous reviewers of this paper for their helpful comments, and gratefully acknowledge support for this project from the UK Arts and Humanities Research Council as part of the Design Star PhD Consortium.

\section{References}

Armstrong, L., Bailey, J., Julier, G., and Kimbell, L. (2014) Social Design Futures. AHRC

Bason, C. (Ed.) (2014) Design for Policy, Gower.

\footnotetext{
${ }^{1}$ As of April 2016
} 
Brassett, J., and O'Reilly, J. (2015) Styling the future: A philosophical approach to design and scenarios, Futures.

Brown, T. (2009) Change by design, Harper Collins.

Buchanan, R. (1992) Wicked Problems in Design Thinking. Design Issues, 8, pp. 5-21.

Christiansen, J. (2013) The irrealities of public innovation: Exploring the political epistemology of state interventions and the creative dimensions of bureaucratic aesthetics in the search for new public futures. PhD thesis

Considine, M. (2012) Thinking Outside the Box? Applying Design Theory to Public Policy. Politics \& Policy, 40, pp 704-724.

Cross, N. (2001) Designerly ways of knowing: design discipline versus design science. Design Issues, 17, pp. 49-55.

Dilnot, C. (2008) The Critical in Design (Part One) Journal of Writing in Creative Practice, 1

Dilnot, C. (2014) Is there an ethical role for the history of design? Redeeming through history the possibility of a humane world. Proceedings from the $9^{\text {th }}$ International Committee Design History and Design Studies.

DiSalvo, C. (2009) Design and the Construction of Publics. Design Issues, 25, pp. 48-63.

Dorst, K. (2015) Frame Innovation: Create New Thinking by Design, MIT.

Dorst, K. (2008) Design research: a revolution-waiting-to-happen? Design Studies, 29

Douglas, M. (1986) How Institutions Think, Syracuse University Press.

Dunleavy, P., Margetts, H., Bastow, S., and Tinkler, J. (2005) New Public Management is Dead: Long Live Digital Era Governance. Discussion papers from EDS Innovation Research Programme.

Flinders, M. (2014) Depoliticisation, governance and the state. Policy \& Politics, 42, pp. 135-49.

Foucault, M. (1991) Governmentality, in Burchell, Gordon and Miller (eds) (1991) The Foucault Effect, University of Chicago Press.

Gagliardi, P. (1999) Exploring the aesthetic side of organizational life, in Clegg and Hardy (eds) (1999) Studying Organization: Theory \& Method, SAGE Publications

Jefferies, E., Yee, J., and Tan, L. (2013) Design Transitions: Inspiring Stories, Global Viewpoints, How Design Is Changing, BIS.

Jones, R., Pykett, J., Whitehead, M. (2010) Governing temptation: Changing behaviour in an age of libertarian paternalism. Progress in Human Geography August, 35 pp. 483-501.

Julier, G. (2007) Design practice within a theory of practice. Design principles and practices: an international journal, Vol 1, No 2.

Julier, G. (2007) The culture of design, Sage.

Junginger, S. (2012) Design Concepts and Design Practices in Policy-Making and Public Management: New Challenges and New Opportunities for Policy-Makers and Public Managers. Proceedings of the Sunrise Conference, Roskilde University, Denmark.

Kimbell, L. (2011) Rethinking Design Thinking: Part I. Design and Culture, 3, pp. 285-306.

Kimbell, L. (2013) An inventive practice perspective on designing, PhD thesis, University of ?

Kimbell, L, (2015) Applying Design Approaches to Policymaking: Discovering Policy Lab, University of Brighton and AHRC

King, A., and Crewe, I. (2013) The Blunders of Our Governments, Oneworld Publications.

Latour, B. (2007) Turning around politics: A note on Gerard de Vries' paper, Social Studies of Science, Vol 37/5, pp. 811-820. 
Leggett, W. (2014) The politics of behaviour change: nudge, neoliberalism and the state. Policy \& Politics, 42, pp. 3-19.

Martin, Roger L. (2009) The design of business: why design thinking is the next competitive advantage, Harvard Business Press.

Mckee, K. (2009) Post-Foucauldian governmentality: What does it offer critical social policy analysis? Critical Social Policy, 29, p. 465

Michlewski, K. (2008) Uncovering design attitude: Inside the culture of designers. Organization studies, 29, pp 373-392.

Miller, P. and Rose, N. (1988) The Tavistock Programme: the government of subjectivity and social life, in Sociology, 22, pp. 171-192

RSA (2014) A new policy toolkit. RSA Journal, Issue 4

Shove, E. (2007) The design of everyday life, Berg.

Stone, D. (1988) Policy Paradox: the art of political decision-making, Norton.

Swyngedouw, E. (2005) Governance Innovation and the Citizen: The Janus Face of Governancebeyond-the-State. Urban Studies, 42, pp. 1991-2006.

Tonkinwise, C. (2014) Design Studies: what is it good for? Design and Culture, 6, pp. 5-43

Tonkinwise, C. (2011) A taste for practices: Unrepressing style in design thinking. Design Studies, 32 pp. 533-545.

Tunstall, E. (2007) In design we trust : Design, governmentality, and the tangibility of governance. in Proceedings of IASDR2007 International Association of Societies of Design Research, 12-15th November, Hong Kong Polytechnic University.

Wilkie, A., and Michael, M. (2009) Expectation and Mobilisation: Enacting Future Users. Science, Technology, \& Human Values, Vol 34/4, pp 502-522

Wren-Lewis, S. (2015) The austerity con, London Review of Books, $19^{\text {th }}$ February, pp. 9-11, http://tinyurl.com/k5tge8q (Accessed $9^{\text {th }}$ October 2015) 
About the Authors:

Jocelyn Bailey is a design consultant with service and social design agency Uscreates, and a PhD student at the University of Brighton, funded by the Design Star Consortium. Her research explores the uses of design in political and policy contexts.

Peter Lloyd is Professor of Design at the University of Brighton and the DRS2016 Conference Chair. He is also Associate Editor of the journal Design Studies, and Membership Secretary of the Design Research Society. His research interests are in the area of design process, design thinking, and design ethics. 